\title{
Preparation and hydrodesulfurization properties of cobalt-molybdenum-phosphorous catalysts for removal of dibenzothiophene
}

\author{
${\text { Xuejin } \mathrm{Li}^{1}(\mathbb{1}) \cdot \mathrm{Ke} \text { Qiao }^{1} \cdot \text { Fazle Subhan }^{2} \cdot \text { Wei Xing }}^{1} \cdot$ Xinmei Liu $^{1} \cdot$ \\ Zifeng Yan ${ }^{1}$
}

Received: 6 May 2015/Accepted: 3 July 2015/Published online: 9 August 2015

(c) The Author(s) 2015. This article is published with open access at Springerlink.com

\begin{abstract}
In this study, a series of cobalt-molybdenumphosphorous acid (Co-Mo-P) impregnating solutions with various $\mathrm{Co} / \mathrm{Mo}$ molar ratios $(0.2,0.25,0.3,0.35)$ were synthesized, and desulfurization catalysts were prepared by mixing the solutions with $\gamma-\mathrm{Al}_{2} \mathrm{O}_{3}$ through an incipientwetness impregnation method. The Co-Mo-P supported $\gamma$ $\mathrm{Al}_{2} \mathrm{O}_{3}$ catalysts were tested in the hydrodesulfurization of dibenzothiophene (DBT). The catalysts were characterized by $\mathrm{N}_{2}$ adsorption-desorption isotherms, XRD, py-FT-IR, and HRTEM. Nitrogen adsorption measurements revealed that the as-prepared catalysts possess high specific surface area and appropriate pore size. XRD showed that Co species and Mo species were well dispersed on the surface of $\gamma-\mathrm{Al}_{2} \mathrm{O}_{3}$ with the addition of phosphoric acid. Py-FT-IR showed that the catalyst with a Co/Mo molar ratio of 0.25 exhibited more Lewis and Brønsted acid sites. The stacking number and slab length of $\mathrm{MoS}_{2}$ nanoclusters changed with various $\mathrm{Co} / \mathrm{Mo}$ molar ratios as revealed by HRTEM. Among the tested catalysts, Co-Mo-P supported $\gamma-\mathrm{Al}_{2} \mathrm{O}_{3}$ with $\mathrm{Co} / \mathrm{Mo}$ molar ratio of 0.25 exhibited higher activity and selectivity of biphenyl than the other catalysts.
\end{abstract}

Keywords CoMoP catalyst · Hydrodesulfurization · Dibenzothiophene

Zifeng Yan

zfyancat@upc.edu.cn

1 State Key Laboratory of Heavy Oil Processing, PetroChina Key Laboratory of Catalysis, China University of Petroleum, Qingdao 266580, China

2 Department of Chemistry, Abdul Wali Khan University Mardan, K.P.K, Mardan, Pakistan

\section{Introduction}

The production of low-sulfur fuels has become very important due to the increasingly stringent environmental regulations imposed by governments worldwide in the last decade. For example, the governments of United States and Japan have already projected new specifications for sulfur in diesel to be lower than 0.0015 and $0.0010-0.0015 \mathrm{wt} \%$ [1]. As is well known to everyone, sulfur species in fuels not only lead to acidic rain but also affect the efficiency of catalytic converters in cars. [2]. To date, hydrodesulfurization (HDS) technique is one of the best conventional methods for removal of sulfur compounds, because of its high efficiency and low environmental pollution [3]. Oilcontaining sulfur compounds are mainly divided into nonthiophene-type sulfides and thiophene-type sulfides. Nonthiophene-type sulfides consist of thiol and sulfoether while thiophene-type sulfides include thiophene, benzothiophene, dibenzothiophenes and alkyl dibenzothiophene. Dibenzothiophenes, particularly those with methyl groups in the 4 and 6 positions (4-MDBT and 4, 6-DMDBT), are among the most refractory S-containing molecules in the oil feed $[4,5]$. These molecules are especially difficult to convert because of the increased stability of S heteroatoms by the aromatic nature of the thiophene ring, and the sterically hindered position of the sulfur atom by both the benzene rings and the methyl groups in the molecule [6]. Removal of these refractive sulfur compounds is necessary to achieve the specifications for ultra-low-sulfur diesel fuel. In order to obtain ultra-low-sulfur diesel fuel, optimization of HDS catalysts in HDS process is the most appropriate approach to minimize the capital investment and lower operating cost.

Supported hydrogenation catalyst is mainly composed of active components, additive and carrier. Recently, the 
active components of hydrogenation catalysts are composed of one or two VI B or VIII B group transition elements such as W, Mo, Co or Ni. Among them, the activity for HDS decreases in the order $\mathrm{Co}-\mathrm{Mo}>\mathrm{Ni}-\mathrm{Mo}>\mathrm{Ni}-$ $\mathrm{W}>\mathrm{Co}-\mathrm{W}$. Sulfided $\mathrm{Co}-\mathrm{Mo}$ catalyst is most frequently reported for hydrodesulfurization. This catalyst still needs further studies to reduce its repaid deactivation and wasteful hydrogen consumption by hydrocracking and hydrogenation reaction. The cobalt-molybdenum composition also has significant influence on the activity of the catalysts. Al-Zeghayer et al. [7] researched the effects of $\mathrm{Co} / \mathrm{Mo}$ ratio on the activity of $\mathrm{CoMo} / \gamma-\mathrm{Al}_{2} \mathrm{O}_{3}$ and found that the catalyst with $\mathrm{Co} / \mathrm{Mo}$ of 0.4 had the highest rate constant for constants of DBT. However, the effect of Co/ Mo on the physicochemical property was not studied. Nikulshin et al. [8] also investigated the effect of Co/Mo ratio and found out that catalysts with $\mathrm{Co} /$ $(\mathrm{Co}+\mathrm{Mo})=0.35$ had maximal activities in 4,6-DMDBT HDS. The acid properties of the prepared catalyst were not studied as well which is important to understand the influence of Co species. In addition, a detailed study of the effect of $\mathrm{Co} / \mathrm{Mo}$ molar ratio on the physicochemical properties and activity of the catalyst is essential. Additive is also important to improve the activity, selectivity and stability performance of hydrogenation catalyst. The addition of phosphate or fluorine not only improves the cracking activity of $\mathrm{C}-\mathrm{N}$ bond, but also enhances the hydrogenation activity of catalysts [9-11]. This can also improve the capacity of active components to increase the utilization of reactive metals. Alumina-supported cobaltmolybdenum catalyst is the most common HDS catalyst, which has been widely used in industrial HDS processes during the last few decades [12-14]. It is believed that the sulfur vacancies at the edges of the $\mathrm{MoS}_{2}$ crystallites are very important to catalytic activity [15]. The active phase in the catalyst is the so-called Co-Mo-S phase in which Co atoms located at the edges of the $\mathrm{MoS}_{2}$ planes constitute the active sites for sulfur extraction [16]. It has been reported that complete sulfidation of the molybdenum phase leads to the so-called type II Co(Ni)-Mo-S sites, that are more active than the partially sulfided type I sites, which strongly interact with the catalyst support via Mo-O bridges [17]. The production of highly active HDS catalysts depend on a greater extent to the level of promotion obtained during catalyst preparation. To increase the number of promoted $\mathrm{Co}(\mathrm{Ni})-\mathrm{Mo}-\mathrm{S}$ sites, it is desirable for the $\mathrm{Co}(\mathrm{Ni})$ and $\mathrm{Mo}$ atoms to be extremely close during the activation (sulfidation) of the catalyst. In addition, the mixing molar ratios of different active metals are also important to the HDS activity. In this context, a detailed study of the preparation and application of Co-Mo-P HDS catalyst is highly required.
Herein, we prepared a Co-Mo-P HDS catalyst with high desulfurization efficiency and selectivity. The influence of $\mathrm{Co} / \mathrm{Mo}$ molar ratio on the catalyst activity was investigated. Different characterization techniques were used to study the morphology, crystallinity, textural properties and acid property of the prepared catalyst in detail. Furthermore, the HDS performance was also carried out in a highpressure microreactor.

\section{Experimental}

\section{Materials}

Phosphoric acid (AR), molybdenum trioxide (AR), DBT (98\%), carbon disulfide $\left(\mathrm{CS}_{2}, \mathrm{AR}\right)$, methylbenzene (AR) were purchased from Sinopharm Chemical Reagent Co. Ltd. Cobaltous dihydroxycarbonate (industrial grade) was purchased from Shen Sheng Catalyst Co. Ltd. $\gamma-\mathrm{Al}_{2} \mathrm{O}_{3}$ (industrial grade) was purchased from Fushun petrochemical company. All chemicals were used as received.

\section{Preparation of cobalt-molybdenum-phosphorous impregnating solutions}

Cobalt-molybdenum-phosphoric acid (Co-Mo-P) impregnating solution was synthesized in the following way. First, a certain amount of phosphoric acid and $50 \mathrm{~mL}$ deionized water was added to the beaker, heated and stirred at $90{ }^{\circ} \mathrm{C}$. Then, the required amount of molybdenum trioxide was added to the boiling phosphoric acid solution. After the solution changed from gray to yellow, a quantity of cobaltous dihydroxycarbonate was slowly added. The whole mixture was continuously stirred and heated until it turned into a burgundy and clear solution. The $\mathrm{Co} / \mathrm{Mo}$ molar ratio during synthesis was maintained at $0.20,0.25$, 0.30 and 0.35 .

\section{Preparation of desulfurization catalyst}

The desulfurization catalyst was prepared via an incipientwetness impregnation method using $\gamma-\mathrm{Al}_{2} \mathrm{O}_{3}$ as catalyst carrier and $\mathrm{Co}-\mathrm{Mo}-\mathrm{P}$ as an active component. After impregnation, the samples were dried at $120{ }^{\circ} \mathrm{C}$ for $6 \mathrm{~h}$ and then calcined at $450{ }^{\circ} \mathrm{C}$ for $3 \mathrm{~h}$ to obtain the required $\mathrm{Co}-$ Mo-P HDS catalysts. The total loading of metal oxide $\left(\mathrm{MoO}_{3}\right.$ and $\left.\mathrm{CoO}\right)$ was $26 \mathrm{wt} \%$. The $\mathrm{Co}-\mathrm{Mo}-\mathrm{P}$ HDS catalysts with different $\mathrm{Co} / \mathrm{Mo}$ molar ratios were denoted as HDC-x (where $\mathrm{x}$ is the Co/Mo molar ratios and $\mathrm{x}=0.20$, $0.25,0.30$ and 0.35 ). 


\section{Characterization of the catalysts}

Nitrogen adsorption measurements were performed on a TriStar 3000 analyzer (Micromeritics, USA). The total surface area was calculated using Brunauer-EmmettTeller (BET) method. The mesopore surface area, mesopore volumes and pore size distribution were obtained from the desorption branch by Barret-Joyner-Halenda (BJH) method. X-ray diffraction (XRD) patterns for the samples were recorded on a Panalytical Xpert PRO X-ray diffractometer with $\mathrm{Cu} \mathrm{K} \alpha$ radiation $(\gamma=1.5406 \AA$, $45 \mathrm{kV}$, $40 \mathrm{~mA}$ ). FT-IR spectra of samples with pyridine (Py) adsorption were recorded on a Nicolet 6700 spectrometer equipped with an MCT liquid-nitrogen-cooled detector and a $\mathrm{KBr}$ beam splitter. In a typical procedure, catalysts were ground into a fine powder and transferred into a ceramic cup. The samples were degassed at $400{ }^{\circ} \mathrm{C}$ for $2 \mathrm{~h}$ under flowing dry $\mathrm{N}_{2}(30 \mathrm{~mL} / \mathrm{min})$. The system was then cooled to $50{ }^{\circ} \mathrm{C}$ under the vacuum conditions, and sample spectra without pyridine were recorded as the background spectra. Pyridine vapor was introduced in an $\mathrm{N}_{2}$ stream online for about $1 \mathrm{~h}$ and then shut off. The system was equilibrated at constant temperature of $150{ }^{\circ} \mathrm{C}$ and $<2 \times 10^{-3} \mathrm{~Pa}$ for $1 \mathrm{~h}$. The equilibration time was determined at $1 \mathrm{~h}$, because the spectra recorded did not show any change after $1 \mathrm{~h}$ of equilibration. Thereafter, the system was cooled to $50{ }^{\circ} \mathrm{C}$, and the spectra of sample after pyridine adsorption were recorded by subtracting the background spectra without pyridine. The spectra of the samples were recorded by accumulating 64 scans at of $4 \mathrm{~cm}^{-1}$ resolution. The amount of pyridine absorbed on different acid sites of the catalyst was obtained from infrared transmittance spectroscopy. Transmission electron microscopy (TEM) was performed with JEOL JEM-2100UHRoperated at $200 \mathrm{kV}$.

\section{Catalytic evaluation}

Catalyst activity measurements of DBT desulfurization were carried out in a high-pressure fixed-bed down-flow micro reactor. $0.5 \mathrm{~g}$ of HDC-x catalyst with particle size of 20-40 mesh was mixed with $2.5 \mathrm{ml}$ of quartz sand placed in the center of the reactor. The catalyst was dried at $120{ }^{\circ} \mathrm{C}$ for $3 \mathrm{~h}$ and then pre-sulfurized oil (Jet fuel oil with $2 \% \mathrm{CS}_{2}$ ) was pumped into the reactor. The catalyst was pre-sulfurized at $330{ }^{\circ} \mathrm{C}$ for $8 \mathrm{~h}$. Then, the temperature was cooled down to $320{ }^{\circ} \mathrm{C}$ and $2 \mathrm{wt} \%$ DBT toluene solution was injected by a micro-syringe pump (Beijing Sheng Yi Tong Technology Development Co., LTD/DSP-2) into the reactor and the reaction was carried out at a pressure of $2.0 \mathrm{MPa}$, a $\mathrm{H}_{2}$ /feed ratio of 300 and a weight hourly space velocity (WHSV) of $2.0 \mathrm{~h}^{-1}$ for $4 \mathrm{~h}$. The liquid product was collected and analyzed by a Varian 3800 gas chromatograph (flame ionization detector, a $50 \mathrm{~m}$ OV101 capillary column) coupled with a quadrupole mass spectrometer (FinniganSSQ710) (GC-MS). Then the temperature was reduced to $280{ }^{\circ} \mathrm{C}$ and reacted for another $4 \mathrm{~h}$ to collected products.

\section{Results and discussions}

\section{Texture properties of HDC-x catalysts}

$\mathrm{N}_{2}$ adsorption-desorption isotherms and pore size distribution of the prepared catalysts are shown in Fig. 1. The adsorption isotherms of all catalysts are of type IV with a $\mathrm{H} 2$ hysteresis loop at relative pressure ranging from 0.4 to 1.0 , which is the characteristic of ink-bottle pores. However, the hysteresis loops of HDC-x are smaller than that of $\gamma-\mathrm{Al}_{2} \mathrm{O}_{3}$ carrier, owning to the insertion of active component in the pore channels (Fig. 1a). As shown in the pore size distribution curves, the pore size distributed mainly at $7.0 \mathrm{~nm}$ which is favourable for the diffusion of sulfides. The specific surface area and pore volume were decreased after the active component was loaded over the carrier. This is because that the active component can occupy a part of surface area and the pore structure would collapse to a certain extent. The active components could insert into the pore channel of $\gamma-\mathrm{Al}_{2} \mathrm{O}_{3}$ carrier, which would transform into metal oxide during the calculation and block a part of pores, resulting in the decrease of specific surface area. In addition, the pores collapsed partly during the calculation process, which could also decrease the specific surface area. All catalysts have similar surface area and pore volume as they have same active component loading. They all have an average pore size of $9.2 \mathrm{~nm}$, which is favor to the diffusion of reactant during the desulfurization process. In addition, large surface area can provide much more active sites for hydrodesulfurization, as the reaction mainly occurred on the surface of the catalysts.

\section{XRD analysis}

The HDC-x catalysts were characterized by XRD and the results are shown in Fig. 2. As can be seen, all catalysts and carrier exhibited diffraction peaks at $2 \theta$ of 45.9 and $67^{\circ}$, which are the characteristic peaks of $\gamma-\mathrm{Al}_{2} \mathrm{O}_{3}[18,19]$. The peak at $26.4^{\mathrm{O}}$ is the characteristic peak of $\mathrm{AlPO}_{4}$ [20], indicating that phosphoric acid was reacted with $\gamma-\mathrm{Al}_{2} \mathrm{O}_{3}$ carrier during impregnation process. It is worth noting that there is no characteristic peak of molybdenum and cobalt species in the XRD patterns, suggesting that the interaction of phosphoric acid and carrier weakened the connection between $\gamma-\mathrm{Al}_{2} \mathrm{O}_{3}$ and $\mathrm{Co}$ or Mo species. Hence, increases the dispersion of Co or Mo over the surface of carrier, leading to an increased catalytic performance of the

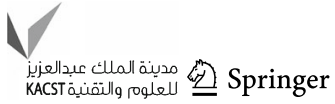


Fig. 1 a $\mathrm{N}_{2}$ adsorptiondesorption isotherms and $\mathbf{b}$ Pore size distributions of HDC- $x$ catalysts
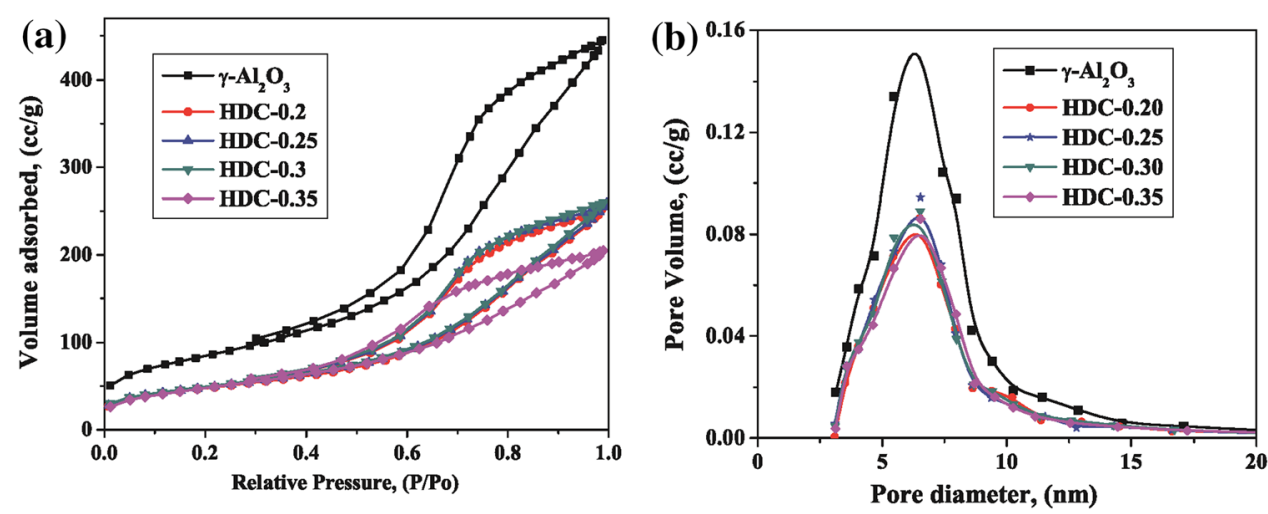

Fig. 2 The XRD patterns of HDC-x catalysts a before and b after reaction
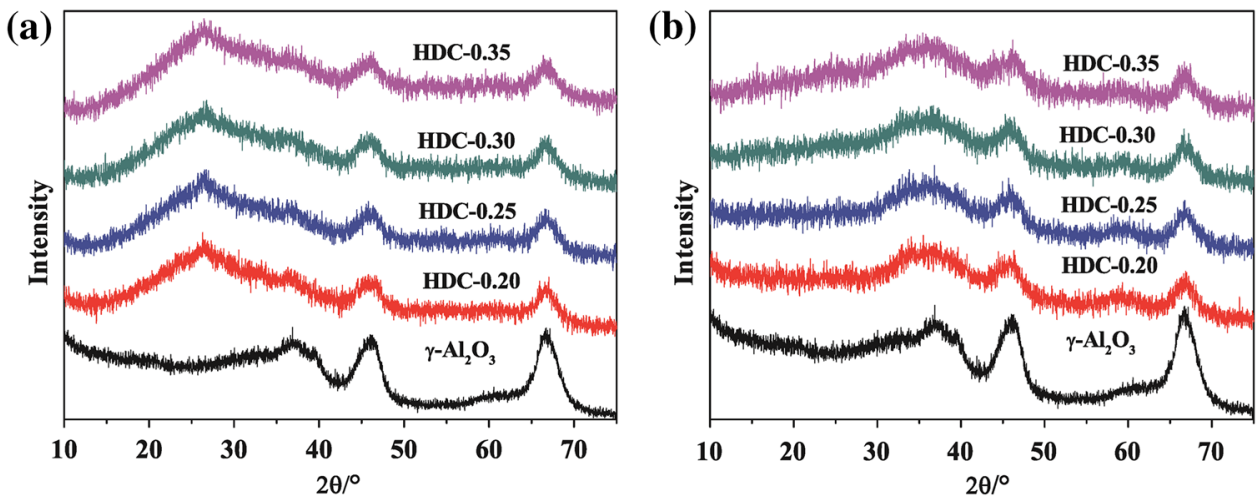

catalysts. The XRD patterns of the catalysts after catalytic reaction were also performed. It can be observed that the diffraction peak of $\mathrm{AlPO}_{4}$ has dispersed while new peaks at $35.5^{\circ}$ and $58.6^{\circ}$ emerged. These two new peaks confirmed the existence of $\mathrm{MoS}_{2}$ [21], indicating that $\mathrm{MoO}_{3}$ has been converted into $\mathrm{MoS}_{2}$ during the pre-sulfurization and reaction process. The easy and complete transformation of $\mathrm{MoS}_{2}$ makes the prepared catalyst present an excellent catalytic performance. In addition, the low diffraction peak intensity demonstrated the small crystal size of $\mathrm{MoS}_{2}$.

\section{Py-FT-IR of HDC-x catalysts}

Appropriate acid properties not only optimize the dispersion of active component on the carrier, but also improve the interaction between active component and carrier. In addition, the appropriate acid can also alleviate the coking of catalyst to extend its operation life. Meanwhile, the Brønsted (B) acid sites have a large promotion to hydrodenitrogenation reaction. The pyridine adsorption FT-IR spectra of HDC-x catalysts are depicted in Fig. 3. It can be seen that all $\mathrm{HDC}-\mathrm{x}$ and $\gamma-\mathrm{Al}_{2} \mathrm{O}_{3}$ present three adsorption peaks at 1443,1490 , and $1540 \mathrm{~cm}^{-1}$. The bands at 1443 and $1540 \mathrm{~cm}^{-1}$ are assigned to the adsorption of pyridine on Lewis (L) and B acid sites, respectively, while band at $1490 \mathrm{~cm}^{-1}$ is attributed to the combined effect of B and L

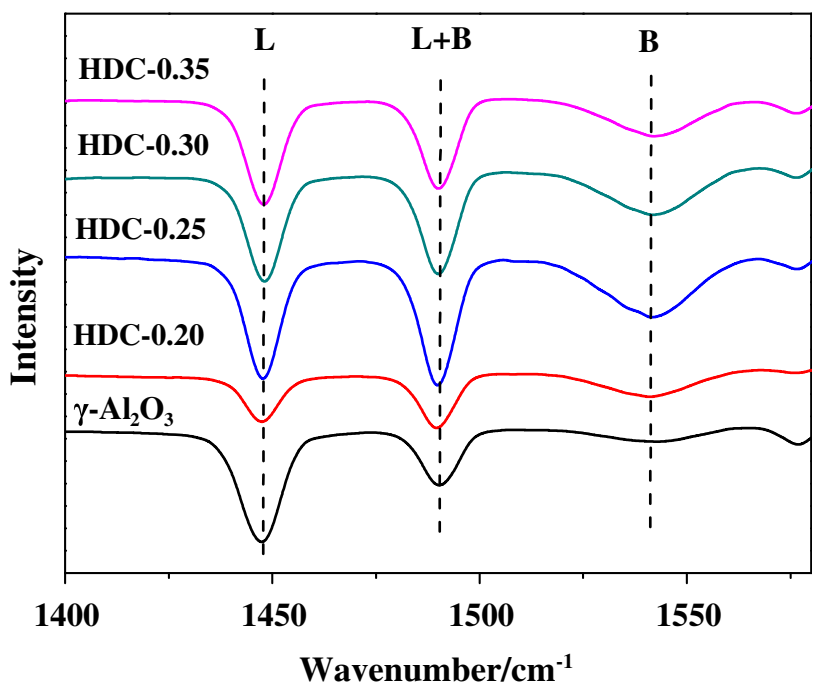

Fig. 3 Pyridine adsorption FT-IR diffuse reflection spectra of HDC-x catalysts

acid sites [22]. From the integral area of the peaks, we can state that all catalysts possess larger amount of $\mathrm{L}$ acid sites than that of $\mathrm{B}$ acid sites. Compared with pure $\gamma-\mathrm{Al}_{2} \mathrm{O}_{3}$ carrier, all HDC-x catalysts have more $\mathrm{B}$ acid sites which come from the active component. It is worth noting that HDC- 0.25 has larger amounts of both L and B acid than 
other catalysts, which play a significant role in the HDS reaction. Appropriate acidity of HDC- 0.25 can not only optimize the dispersion of $\mathrm{MoS}_{2}$ and improve the interaction between $\mathrm{MoS}_{2}$ and $\gamma-\mathrm{Al}_{2} \mathrm{O}_{3}$, but also decrease the coking of catalysts and prolong use life of catalyst. Moreover, the large amount $\mathrm{B}$ acid sites have positive promotion on the HDN reaction.

\section{HRTEM of HDC-x catalysts}

HRTEM characterizations of HDC-x catalysts were carried out to obtain more information about the structure of active $\mathrm{MoS}_{2}$ nanoclusters on the surface of carrier. The HRTEM micrographs are shown in Fig. 4. The black thread-like fringes correspond to the $\mathrm{MoS}_{2}$ slabs. The fringes observed in the images had a spacing of about $0.61 \mathrm{~nm}$ that was the characteristic of (002) basal planes of crystalline $\mathrm{MoS}_{2}$. Researchers usually collect statistics to analyze the properties of $\mathrm{MoS}_{2}$ crystal cluster. Here we measured the stacking numbers and slab length of more than $600 \mathrm{MoS}_{2}$ crystal. The average stacking numbers $\left(N_{A}\right)$ and slab length $\left(L_{A}\right)$ are calculated via the following formula and listed in Table 1.

$N_{A}=\sum_{i=1}^{m} m_{i} N_{i} / \sum_{i=1}^{m} m_{i}$

$L_{A}=\sum_{i=1}^{m} m_{i} L_{i} / \sum_{i=1}^{m} m_{i}$

where $\mathrm{m}$ is the number of the $\mathrm{MoS}_{2}$ crystal clusteres that we measured, $N_{i}$ is the stacking number, $L_{i}$ is the slab length $(\mathrm{nm})$.

Fig. 4 HRTEM images of a HDC- 0.20 , b HDC- 0.25 , c HDC-0.30, d HDC-0.35 after HDS reaction
Table 1 Average stacking numbers and slab length of HDC-x catalysts

\begin{tabular}{lll}
\hline Catalysts & $N_{A}$ & $L_{A} / \mathrm{nm}$ \\
\hline HDC-0.20 & 2.5 & 3.58 \\
HDC-0.25 & 3.1 & 3.29 \\
HDC-0.30 & 2.9 & 3.51 \\
HDC-0.35 & 2.6 & 3.95 \\
\hline
\end{tabular}

All catalysts exhibit stacking numbers ranging from 2 to 3 and slab length of more than $3.0 \mathrm{~nm}$. It is obvious that HDC-0.25 has the highest stacking number and shortest slab length, suggesting that $\mathrm{MoS}_{2}$ was highly dispersed on the surface of the carrier. Such structure with higher stacking number and shorter slab length is favorable for exposing more active sites, leading to higher catalytic activity. Furthermore, $\mathrm{MoS}_{2}$ with higher stacking number possesses more hydrogenation active centers which could improve the hydrogenation selectivity of the catalyst.

\section{DBT catalytic evaluation}

The hydrodesulfurization reactions of DBT were carried out in a fixed-bed high-pressure reactor over the HDC-x catalysts, and the influences of $\mathrm{Co} / \mathrm{Mo}$ molar ratio on the conversion of DBT and products distributions were investigated. The results are presented in Fig. 5. Figure 5a shows that the hydrogenation desulfurization efficiency increases with the increase of Co/Mo molar ratio at 280 and $320{ }^{\circ} \mathrm{C}$. It is obvious that almost all the sulfides were
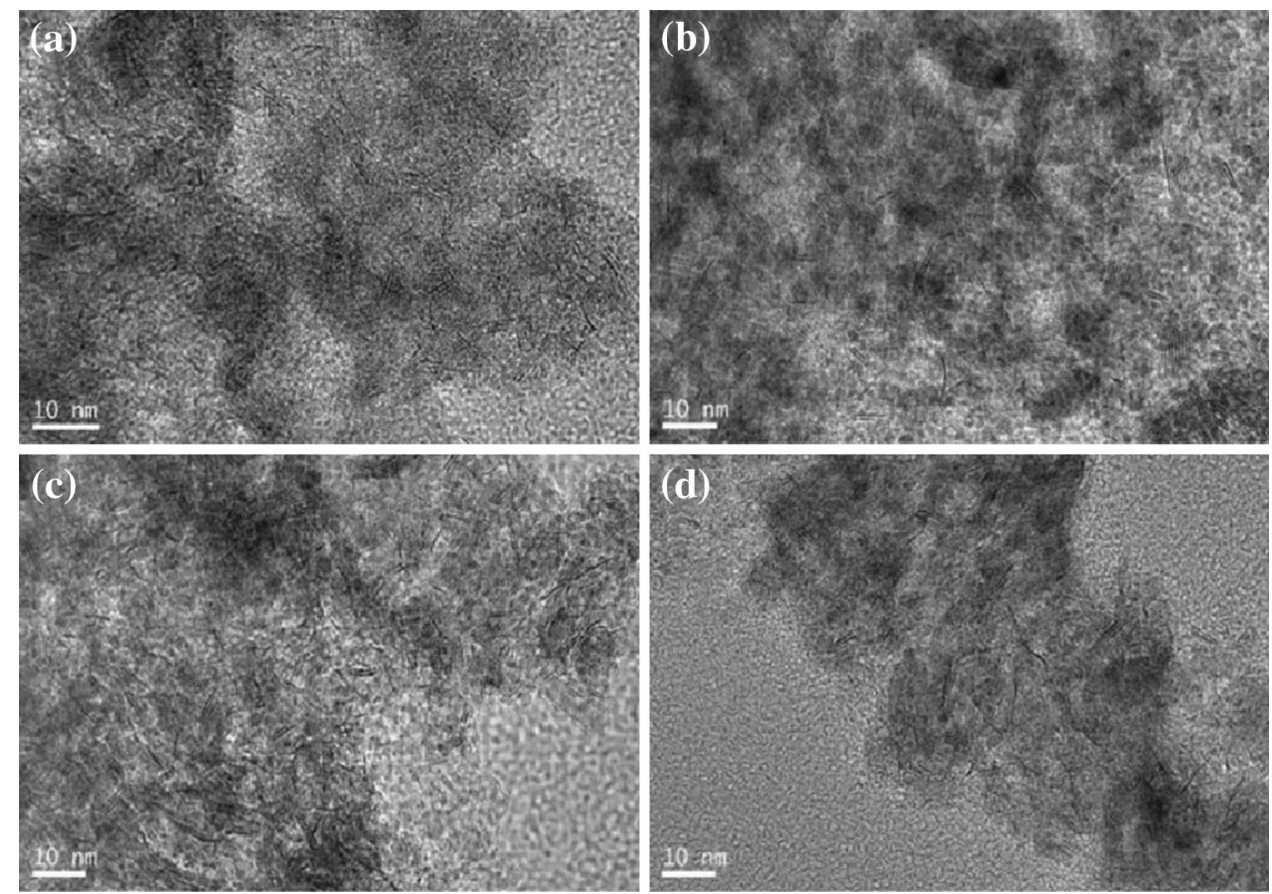

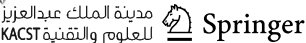


Fig. 5 a Hydrogenation desulfurization percent of HDC$\mathrm{x}$ catalysts at 280 and $320^{\circ} \mathrm{C}$; b products distribution over HDC-x catalysts at $280{ }^{\circ} \mathrm{C}$ and c $320^{\circ} \mathrm{C}$; d BP selectivity of HDC-x catalysts at 280 and $320{ }^{\circ} \mathrm{C}$
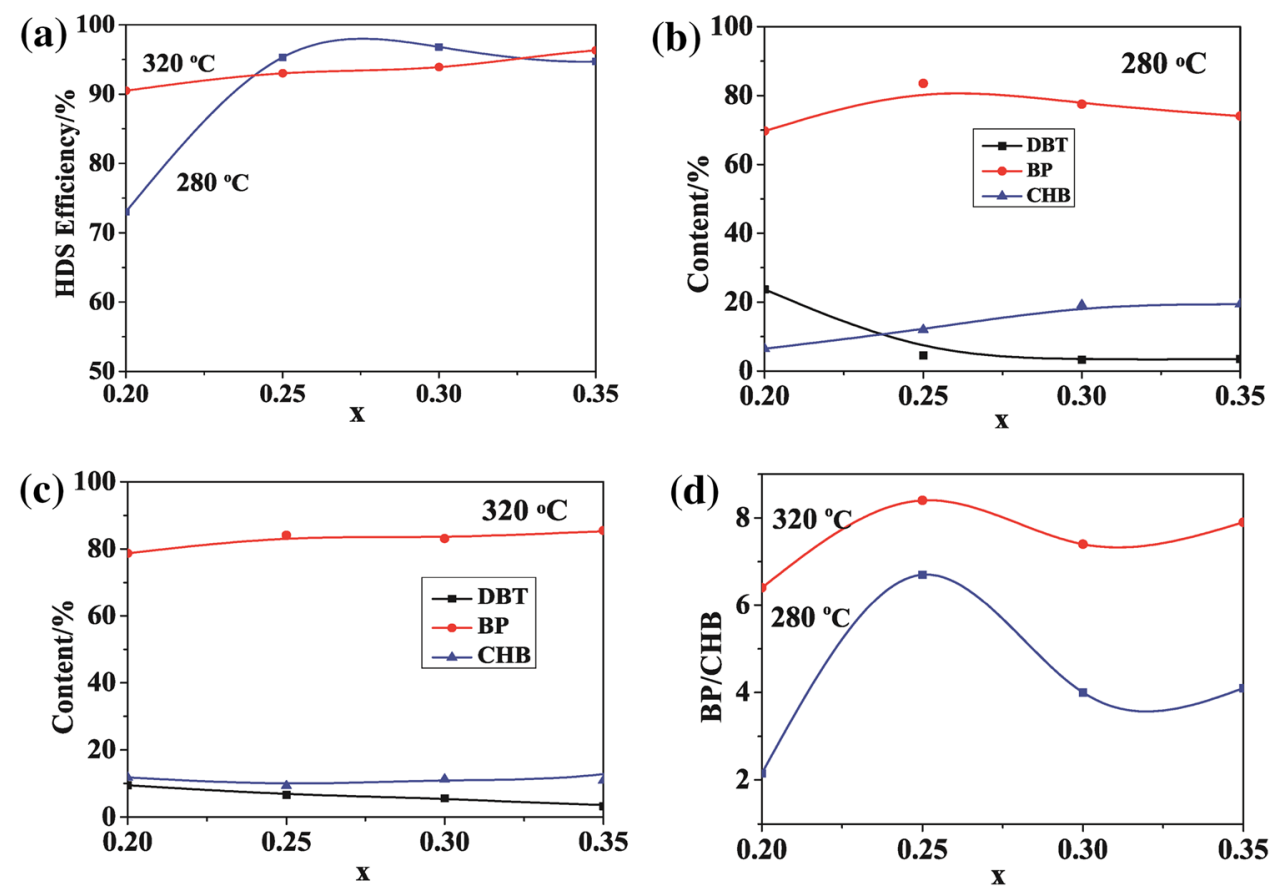

removed. When $\mathrm{Co} / \mathrm{Mo}$ molar ratios were in the range $0.25-0.35$, there is not much difference in the desulfurization rate at 280 and $320{ }^{\circ} \mathrm{C}$, indicating that reaction temperature is not the main factor affecting the desulfurization rate. There are extensive studies on the mechanism of HDS reaction, revealing that DBT and its derivates undergo through two reaction routes named as DDS and HYD $[23,24]$. The $\mathrm{C}-\mathrm{S}$ bonds of DBTs are broken through hydrogenolysis or elimination (including the anti-elimination), and biphenyl (BP) is formed in the DDS route, whereas in the HYD route, one of the aromatic rings of DBT is first hydrogenated to intermediates such as 1, 2, 3, 4-tetrahydrodibenzothiophene (THDBT) and hexahydrodibenzothiophene (HHDBT), and possibly the two aromatic rings are completely hydrogenated to form dodecahydrodibenzothiophene (DHDBT). Then, the sulfur is removed to form cyclohexylbenzene (CHB) [24, 25]. As shown in Fig. 5b, c, the conversion of DBT increased with the increase of $\mathrm{Co} / \mathrm{Mo}$ molar ratio, and $\mathrm{BP}$ and $\mathrm{CHB}$ are the main products over HDC-x catalysts under 280 and $320{ }^{\circ} \mathrm{C}$. The contents of BP are much higher than that of CHB for all catalysts at 280 and $320^{\circ} \mathrm{C}$, indicating that the HDS are mainly processed via DDS route. The selectivity of BP over HDC-x catalysts was calculated and the results are shown in Fig. 5d. From Fig. 5d, the selectivity of BP was the highest over HDC- 0.25 catalyst both at 280 and $320{ }^{\circ} \mathrm{C}$. In addition, the selectivity of BP over all the catalysts are higher at $320^{\circ} \mathrm{C}$ than that at $280^{\circ} \mathrm{C}$, suggesting that HDS prefer to proceed via DDS route at higher temperature.

\section{Conclusion}

In summary, a series of cobalt-molybdenum-phosphorus hydrodesulfurization catalysts with various $\mathrm{Co} / \mathrm{Mo}$ molar ratios were synthesized by an incipient-wetness impregnation method. The as-prepared catalysts have large surface area, appropriate pore size and large amount of acid sites, leading to excellent desulfurization performance. Furthermore, the addition of phosphoric acid improves the dispersion of Co and Mo species, which also enhance the catalytic performance. The results show that the variation of Co/Mo molar ratio has minor influence on the textual properties of the as-prepared catalysts while affecting the acid properties significantly. The hydrogenation desulfurization rate of HDC- 0.25 catalyst was especially high and it was mainly processed via DDS route.

Acknowledgments This work was financially supported by National Natural Science Foundation of China (21376267).

Open Access This article is distributed under the terms of the Creative Commons Attribution 4.0 International License (http:// creativecommons.org/licenses/by/4.0/), which permits unrestricted use, distribution, and reproduction in any medium, provided you give appropriate credit to the original author(s) and the source, provide a link to the Creative Commons license, and indicate if changes were made.

\section{References}

1. García-Gutiérrez JL, Laredo GC, Fuentes GA, García-Gutiérrez P and F Jiménez-Cruz (2014) Effect of nitrogen compounds in the 
hydrodesulfurization of straight-run gas oil using a $\mathrm{CoMoP} / \mathrm{g}$ $\mathrm{Al}_{2} \mathrm{O}_{3}$ catalyst. Fuel 138:98-103

2. Ebrahimynejad M, Haghighi M (2014) Nanocatalysts: effect of active-phase and promoter on catalytic properties and performance in the hydrodesulfurization reaction. Petrol Sci Technol $32: 2867-2877$

3. Xu W, Wang X, Zhou Q, Meng B, Zhao J, Qiu J, Gogotsi Y (2012) Low-temperature plasma-assisted preparation of graphene supported palladium nanoparticles with high hydrodesulfurization activity. J Mater Chem 22:14363-14368

4. Ma X, Sakanishi K, Mochida I (1994) Hydrodesulfurization reactivities of various sulfur compounds in diesel fuel. Ind Eng Chem Res 33:218-222

5. Shafi R. Hutchings GJ (2000) Hydrodesulfurization of hindered dibenzothiophenes: an overview. Catal Today 59:423-442

6. Tuxen AK, Füchtbauer HG, Temel B, Hinnemann B, Topsøe H, Knudsen KG, Besenbacher F, Lauritsen JV (2012) Atomic-scale insight into adsorption of sterically hindered dibenzothiophenes on MoS2 and Co-Mo-S hydrotreating catalysts. J Catal 295:146-154

7. Al-Zeghayer Y, Sunderland P, Al-Masry W, Al-Mubaddel F, Ibrahim A, Bhartiya B, Jibril B (2005) Activity of $\mathrm{CoMo} / \gamma-\mathrm{Al}_{2} \mathrm{O}_{3}$ as a catalyst in hydrodesulfurization: effects of $\mathrm{Co} / \mathrm{Mo}$ ratio and drying condition. Appl Catal A Gen 282:163-171

8. Nikulshin PA, Mozhaev AV, Pimerzin AA, Konovalov VV, Pimerzin AA (2012) $\mathrm{CoMo} / \mathrm{Al}_{2} \mathrm{O}_{3}$ catalysts prepared on the basis of $\mathrm{Co}_{2} \mathrm{Mo}_{10}$-heteropolyacid and cobalt citrate: effect of $\mathrm{Co} / \mathrm{Mo}$ ratio. Fuel 100:24-33

9. Du Y, Feng D, Wan J, Ma X (2014) The enhanced asymmetric hydrogenation of unsymmetrical benzils to hydrobenzoin catalyzed by organosoluble zirconium phosphonate-immobilized ruthenium catalyst. Appl Catal A Gen 479:49-58

10. Zhang S, Song L, Wu X (2014) A new preparation approach for $\mathrm{NiCoP} / \mathrm{SiO}_{2}$ catalyst by solid phase reaction of nickel and cobalt cations with potassium dihydrogen phosphate. Ceram Int 40:5339-5342

11. Tuteja J, Choudhary H, Nishimura S, Ebitani K (2014) Direct synthesis of 1, 6-hexanediol from HMF over a heterogeneous Pd/ $\mathrm{ZrP}$ catalyst using formic acid as hydrogen source. ChemSusChem 7:96-100

12. Gao Q, Ofosu TNK, Ma S-G, Komvokis VG, Williams CT, Segawa K (2011) Catalyst development for ultra-deep hydrodesulfurization (HDS) of dibenzothiophenes. I: effects of $\mathrm{Ni}$ promotion in molybdenum-based catalysts. Catal Today 164:538-543

13. Ge H, Wen X-D, Ramos MA, Chianelli RR, Wang S, Wang J, Qin Z, Lyu Z, Li X (2014) Carbonization of ethylenediamine coimpregnated $\mathrm{CoMo} / \mathrm{Al}_{2} \mathrm{O}_{3}$ catalysts sulfided by organic sulfiding agent. ACS Catal 4:2556-2565

14. Nikulshin P, Ishutenko D, Mozhaev A, Maslakov K, Pimerzin A (2014) Effects of composition and morphology of active phase of $\mathrm{CoMo} / \mathrm{Al}_{2} \mathrm{O}_{3}$ catalysts prepared using $\mathrm{Co}_{2} \mathrm{Mo}_{10}$-heteropolyacid and chelating agents on their catalytic properties in HDS and HYD reactions. J Catal 312:152-169

15. Romero-Galarza A, Gutiérrez-Alejandre A, Ramírez J (2011) Analysis of the promotion of $\mathrm{CoMoP} / \mathrm{Al}_{2} \mathrm{O}_{3}$ HDS catalysts prepared from a reduced H-P-Mo heteropolyacid Co salt. J Catal 280:230-238

16. Topsoe H, Clausen BS (1984) Importance of Co-Mo-S type structures in hydrodesulfurization. Catal Rev 26:395-420

17. Brorson M, Carlsson A, Topsøe H (2007) The morphology of $\mathrm{MoS}_{2}, \mathrm{WS}_{2}$, Co-Mo-S, Ni-Mo-S and Ni-W-S nanoclusters in hydrodesulfurization catalysts revealed by HAADF-STEM. Catal Today 123:31-36

18. Yao M, Baird R, Kunz F, Hoost T (1997) An XRD and TEM investigation of the structure of alumina-supported ceria-zirconia. J Catal 166:67-74

19. Dow W-P, Wang Y-P, Huang T-J (2000) TPR and XRD studies of yttria-doped ceria/ $\gamma$-alumina-supported copper oxide catalyst. Appl Catal A General 190:25-34

20. Wignall G, Rothon R, Longman G, Woodward G (1977) The structure of amorphous aluminium phosphate by radial distribution functions derived from X-ray diffraction. J Mater Sci 12:1039-1049

21. Mdleleni MM, Hyeon T, Suslick KS (1998) Sonochemical synthesis of nanostructured molybdenum sulfide. J Am Chem Soc 120:6189-6190

22. Lercher J, Rumplmayr G (1986) Controlled decrease of acid strength by orthophosphoric acid on ZSM5. Appl Catal 25:215-222

23. Wang H, Prins R (2009) Hydrodesulfurization of dibenzothiophene, 4, 6-dimethyldibenzothiophene, and their hydrogenated intermediates over $\mathrm{Ni}-\mathrm{MoS}_{2} / \gamma-\mathrm{Al}_{2} \mathrm{O}_{3}$. J Catal 264:31-43

24. Egorova M, Prins R (2004) Hydrodesulfurization of dibenzothiophene and 4, 6-dimethyldibenzothiophene over sulfided $\mathrm{NiMo} /$ $\gamma-\mathrm{Al}_{2} \mathrm{O}_{3}, \mathrm{CoMo} / \gamma-\mathrm{Al}_{2} \mathrm{O} 3$, and $\mathrm{Mo} / \gamma-\mathrm{Al}_{2} \mathrm{O}_{3}$ catalysts. J Catal 225:417-427

25. Wang H, Prins R (2008) Hydrodesulfurization of dibenzothiophene and its hydrogenated intermediates over sulfided $\mathrm{Mo} / \gamma$ $\mathrm{Al}_{2} \mathrm{O}_{3}$. J Catal 258:153-164 